\title{
The interactive effects of instructional set and environmental context changes on the serial position effect
}

\author{
SARA J. NIXON and N. JACK KANAK \\ University of Oklahoma, Norman, Oklahoma 73019
}

\begin{abstract}
Subjects were first given either conventional acquisition instructions for single-trial free recall or experimental instructions encouraging the use of the general environmental context as a source of potential facilitatory associations. Subjects were then given the recall test on the 35-item list in either the same or a different room context. Subjects receiving experimental instructions gave significantly more correct responses than did control subjects, regardless of test-room context. However, there was an interactive effect of context and the position of the words recalled, with recency items being adversely affected and primacy items facilitated by contextual changes. The overall facilitatory effect of the contextual instruction was due to a significant increase in middle items recalled by the experimental group (i.e., a reduction of the serial position effect).
\end{abstract}

The environmental context effect refers to the phenomenon that individuals who are placed in the context of original learning for testing on the acquired information perform more accurately than do individuals who are placed in a new, unfamiliar, or interfering physical context. This facilitative effect due to "same-context" testing has been illustrated in a number of animal (Zentall, 1970), as well as human (e.g., Abernethy, 1940; Godden \& Baddeley, 1975; Smith, 1979; Smith, Glenberg, \& Bjork, 1978), studies.

Even though the environmental context effect on memory is well documented, the underlying processes, as well as the way in which environmental context might interact with secondary variables such as instructional set or various measures of individual differences, have not been defined. There appears to be little theoretical speculation or systematic investigation of what these proposed associations are or how they might operate in conjunction with additional variables (see Glenberg, 1979; Glenberg, Bradley, Stevenson, Kraus, Tkachuk, Gretz, Fish, \& Turpin, 1980). Most investigators to this point have defined the effects of contextual changes more in terms of an oscillating sort of variable rather than a viable source of manipulation and cognitive change. Within our framework, the environmental context effect is assumed to be due to the development of either incidentally or intentionally learned associations between the physical cues present

A paper based on the experiment reported was presented at the meeting of the Southwestern Psychological Association, Houston, Texas, April 1981. A special thank you should be extended to Sharilyn Nixon, who collected a portion of the raw data. Requests for reprints should be addressed to Sara J. Nixon, Department of Psychology, University of Oklahoma, Norman, Oklahoma 73019. in the environment during learning and the to-belearned items and/or associations. The presence of the same cues during testing is assumed to have the effect of directly eliciting from memory (in the case of incidental learning) or causing the subject to emit or retrieve from memory (in the case of the intentional use of physical cues during learning of the materials) the association between the physical cues and the to-beremembered items and/or associations that facilitates their availability for recall and, perhaps under more restricted circumstances, aids correct discrimination/ recognition. The absence of or interference with these contextual cues at the time of testing leads to a decrement in memory that is assumed to be reduced by the reinstatement of the cues present during acquisition. This general theoretical framework is compatible with the encoding-specificity hypothesis (e.g., Thomson \& Tulving, 1970) and related findings, but it is not based on that hypothesis. At the intuitive level, an example of this phenomenon is the experience of thinking about going from one room to a second to procure something, forgetting what was to be procured after arriving at the second, returning to the first room, and having the memory of what was to be sought reinstated in consciousness either automatically or by specific cues in the first room that prompted the original mission to the second room.

As a fundamental form of associative learning, such contextual associations should be sensitive in their formation to the large range of secondary variables that have been broadly demonstrated to affect other types of associative learning. Among these may be included degree of learning (as defined by the number of trials or exposures on the material to be learned and/or length of exposure to the environmental context following 
initiation of acquisition, the latter of which may also interact with spaced vs. massed practice), salience and meaningfulness of physical cues, and instructional set.

The present study investigates the influence of instructional set regarding the use of environmental cues upon free recall in the same or different environmental contexts. Previous research (e.g., Bugelski, Kidd, \& Segman, 1968) indicates that learning strategies accompanied by imagery instructions facilitate later recall. However, other studies (e.g., Hyde \& Jenkins, 1969) have shown no facilitatory effect due to instructional set. Hyde and Jenkins (1969) suggested that their results were due to subjects' attempting to employ their own idiosyncratic strategies.

The experiment employed a 2 (levels of test context: same or different) by 2 (type of instructions) design. In this experiment, the special instructions to attend to contextual cues (not specific events or objects, but the general context) were given prior to the beginning of the acquisition phase.

It was predicted, first, that if subjects are instructed to utilize contextual cues as a general mnemonic aid at acquisition and if these instructions provide a useful strategy, instructed subjects should recall more items than noninstructed subjects, regardless of test room context.

Second, if subjects are asked to recall in the same physical context as that employed in original learning, rather than a novel context, they should recall more items regardless of instructional set.

\section{METHOD}

\section{Design}

The experiment used a 2 by 2 factorial design employing two levels of test room context (the same as or different from original learning) and two levels of instructions (conventional or general information regarding contextual cues).

\section{Subjects}

This study utilized 64 student volunteers from the introductory psychology pool at the University of Oklahoma who received class credit for their participation.

\section{List}

The 35-item list used was composed exclusively of adjectives selected from the Haagen (1949) norms. The adjectives were selected such that no category was represented more than once within the 35 items. The words were typed in uppercase letters and shown individually on $2 \times 2$ in. slides at 3 -sec intervals. No items on the list were directly or semantically related to any objects in the two room contexts.

\section{Room Context}

Two distinctive environmental contexts were employed for the recall test. The bright context room was a brightly illuminated $18 \times 26 \mathrm{ft}$ room. The room was decorated with various posters and contained various pieces of apparatus. The subject was seated in front of the experimenter in a comfortable chair. The slide screen was attached to the front wall of the room approximately $6.5 \mathrm{ft}$ in front of the subject. All subjects studied the list in the bright context, since previous research from this same laboratory had indicated no differential context effects for the two levels of room illumination on the acquisition of a single list.
The dark context was a dimly lighted $12 \times 8 \mathrm{ft}$ cubicle within a room $12 \times 18 \mathrm{ft}$. Three of the sides were structural walls of concrete blocks painted yellow, and the fourth side was the back of a yellow aluminum bookcase used to partition the cubicle from the rest of the room. The only objects in the cubicle were a stand for the projector, the projector, a straightback chair for the subject located $6.5 \mathrm{ft}$ from the front wall on which the slide screen was attached, and a chair for the experimenter that was located to the right rear of the subject. Both rooms were located among a series of laboratories utilized in psychological research.

\section{Procedure}

Upon arrival at the laboratory, each subject was conducted to the bright room and given the acquisition instructions appropriate to the condition randomly assigned. Those subjects in the experimental instructions group received general instructions to attend to the overall environmental context within the bright room, as well as conventional instructions requisite to the task. These instructions told the subjects that sometimes contextual cues can be helpful in encoding information and requested that the subjects spend a few seconds looking about the room. Those subjects in the control group received conventional acquisition instructions for the task; these instructions made no reference to the items on the list and objects in the room.

After receiving the instructions, each subject viewed a single presentation of the list items at the 3-sec rate. After viewing the entire list, the subjects were asked to step into the hall while the experimenter prepared for the next task, and they were told that they might be asked to move to a different room for the following recall test. This "psychological disruption," which has been proposed as an alternative explanation (Strand, 1970) for the context effect in early studies (Bilodeau \& Schlosberg, 1951; Greenspoon \& Ranyard, 1957), occurred for both those subjects who were to return to the same context for testing and those who were to move to the different room for the recall test. The intertask interval was approximately $15 \mathrm{sec}$, which allowed those subjects who were in the "different" test condition to have time to change to the different context and receive the appropriate recall instructions. All subjects received conventional free recall instructions emphasizing recall in any order. Subjects were given $2 \mathrm{~min}$ for oral free recall and then were debriefed and dismissed.

\section{RESULTS}

Subjects within the experimental instruction group retrieved significantly more items (mean $=11.47)$ than those given conventional instructions (mean $=9.12$ ) $[F(1,60)=10.41, p=.002]$. No other main effects or interactions were significant (all Fs $<1.0$ ).

A main effect for instructional set was also found when the number of item repetitions in recall was analyzed $[F(1,60)=4.70, p=.03]$. Subjects in the experimental instructions condition repeated an average of 1.09 items vs. an average of only .56 items for the control condition. No other effects were found to be significant (all Fs $<1.0$ )

The manipulation of environmental context at testing also leads to a prediction that recency items, which are assumed to be held in short-term memory and are therefore continuing to be in temporal contiguity with environmental cues, should be adversely affected by a change in context. Primacy items, on the other hand, are assumed to be held in long-term memory and no longer are in temporal contiguity with environ- 
mental cues at the conclusion of list presentation. A 2 by 2 analysis was performed on the first (primacy) and last (recency) five items presented, with five items being chosen to ensure the number of recency items was within most subjects' memory span. This analysis produced a marginally significant Test Room Context by Position interaction $[F(1,60)=3.57, p=.06]$. Recency items (mean $=2.53$ ) were better recalled in the same context than were primacy items (mean = 1.78), but they were recalled less well in the different context (mean $=2.00$ ) than in the same context. Primacy items were actually recalled slightly better in the different context (mean $=2.15)$, suggesting a possible release of retroactive interference from later presented items. The instruction main effect and the interaction were nonsignificant (both ps $<.14$ ).

Because no effects due to instructional main effect or interaction were found on the primacy and recency items analysis and yet a main effect for instructions occurred in total correct recall, an additional analysis involving the number of middle items (6-30 inclusive) recalled was conducted. This analysis showed a significant effect due to the type of instruction $[F(1,60)=$ $12.48, p=.001]$. Apparently, the experimental instructions had their most beneficial effect on the middle items, that portion of the list typically the most difficult to recall. The instructed condition retrieved 7.12 items (28\%) on the average, whereas subjects in the control condition retrieved an average of only 4.81 words (19\%) from the middle of the list. Given that only a single exposure was utilized, the $9 \%$ improvement is of practi$\mathrm{cal}$, as well as theoretical, interest.

\section{DISCUSSION}

The data of the present study, although not totally supporting the original hypothesis, do provide some theoretically interesting results. The results indicated only a marginally significant effect due to the environmental context manipulation. This effect was found in the Serial Position by Test Room interaction. Recency items were adversely affected by contextual changes between study and test phases, whereas change to a different context produced some facilitation for primacy items. This finding is particularly interesting in that the recency effect is generally assumed to be due to short-term or working memory, whereas the primacy items appear to be stored in the more resilient, long-term or secondary store (Craik, 1970; Crowder, 1976). If one assumes that these two stores, while not being entirely distinct in their modes of operation, do differ in the primary modes employed, with the long-term store operating mainly with semantic information and the short-term store utilizing phonetic (Loftus \& Loftus, 1976) or perhaps immediate contextual information, then the resultant interaction can be explained. Thus, it appears that this result offers some support for the possibility that the role of environmental context is most salient in situations involving lower levels of processing (Craik \& Lockhart, 1972), rather than in those employing deeper or semantic processing. Consistent with this analysis, other recent studies (e.g., Smith, 1979; Smith et al., 1978) that have indicated an environmental context effect have also typically utilized lists and tasks that do not explicitly rely on semantic processing. Further research directly contrasting differential levels of processing is necessary to directly test the validity of these assumptions. In addition, other variables, such as degree of learning or duration of exposure to the context, may increase the potency of the context effect throughout the length of the list.

Although the context manipulation was not as effective in producing differential recall scores as had been predicted, the type of instructions given did produce fairly consistent results. Providing specific instructions prior to input that contextual cues might be helpful in a later recall test increases overall correct recall and, in particular, the recall of the middle items, thus reducing the serial position effect. If this effect produced by general instructions to become familiar with the environment is robust, it could have important practical application to any type of learning task that produces the classical serial position effect. However, these experimental instructions also resulted in subjects' producing more repetitions of correctly recalled list items. It appears as though subjects begin on a memory journey through the context of original learning but find themselves returning to the specific objects, areas, and so on, of the room and, therefore, repetitiously recall some of the items associated with, however diffusely, those aspects of the context that are most salient to them. Additionally, these data indicate that instructions to attend to various aspects of the context at acquisition may facilitate rehearsal by providing a useful strategy that, in turn, provides the subjects with additional mental cues and thus increases recall scores. The increased rehearsal and number of mental cues may then reduce the detrimental effects of removal of direct elicitation of contextual associations, caused by a change in context, except in situations in which the context has strong associations to the list items or has been utilized as a specific mnemonic source.

A second experiment, which manipulated the instructional set just prior to recall rather than at acquisition, was also conducted. Because no main or interactive effects due to either variable manipulation were obtained, this experiment was not reported. However, it should be noted that the absence of an instructional set effect in the second experiment was not particularly surprising, given the wealth of published data regarding the encoding-specificity hypothesis. In fact, the lack of an effect establishes support, although via the null hypothesis, for the encoding-specificity hypothesis, and especially so when taken in combination with the first study, in which experimental instructions prior to input did increase correct recall.

Even though the absence of a context effect above that produced within the recency/primacy items in the first experiment could be explained via the intentional use of imagery/ context instructions overriding the incidental use of contextual cues, the lack of an analogous effect in the second experiment is more theoretically troublesome in light of the present predictions. Unfortunately, an acceptable rationale is not obvious. It might be observed, however, that most researchers in this area have typically employed lists of substantially longer length and included other manipulations such as a longer retention interval. Such manipulations should have increased task difficulty as well as duration of exposure to the original context and thus, perhaps, also increased a subject's intentional or unintentional use of contextual cues.

Perhaps the context effect is a function not only of specific independent variables previously discussed, such as list length, type of word, degree of learning, and/or duration of exposure, and so on, but also of factors that are generally assumed to be a function of an individual's cognitive style (e.g., field dependency, age, and personality trait differences) or the processing type required by the task, for instance, automatic vs. effortful or controlled processing (Hasher \& Zacks, 1979; Posner \& Snyder, 1975). 


\section{REFERENCES}

Abernethy, E. M. The effect of changed environmental conditions upon the results of college examinations. Journal of Psychology, 1940, 10, 293-301.

Brlodenu, I. M., \& Schlosberg, H. Similarity in stimulating conditions as a variable in retroactive inhibition. Journal of Experimental Psychology, 1951, 41, 199-204.

Bugelsxi, B. R., KIDD, E., \& Seamen, J. Image as a mediator in one-trial paired-associate learning. Journal of Experimental Psychology, 1968, 76, 69-73.

Craik, F. I. M. The fate of primary items in free recall. Journal of Verbal Learning and Verbal Behavior, 1970, 9, 143-148.

Craix, F. I. M., \& Lockhart, R. S. Levels of processing: A framework for memory research. Journal of Verbal Learning and Verbal Behavior, 1972, 11, 671-684.

Crowder, R. B. Principles of learning and memory. Hillsdale, N.J: Erlbaum, 1976.

Glenbera, A. M. Component-levels theory of the effects of spacing of repetitions on recall and recognition. Memory \& Cognition, 1979, 7, 95-112.

Glenberg, A. M., Bradley, M. M., Stevenson, J. A., Kraus, T. A., TkachuK, M. J., Gretz, A. L., Fish, J. H., \& Turpin, B. A. M. A two process account of long-term serial position effects. Journal of Experimental Psychology: Human Learning and Memory, 1980, 6, 355-369.

Godden, D. R., \& Baddeley, A. D. Context dependent memory in two natural environments: On land and underwater. British Journal of Psychology, 1975, 66, 325-331.

Greenspoon, J., \& RANyARD, R. Stimulus conditions and retroactive inhibition. Journal of Experimental Psychology, 1957, 53, 55-59.
HAAGen, C. H. Synonymity, vividness, familiarity, and associationvalue ratings for $\mathbf{4 0 0}$ pairs of common adjectives. Journal of Psychology, 1949, 27, 453-463.

HAsher, L., \& ZACKs, R. T. Automatic and effortful processes in memory. Journal of Experimental Psychology: General, 1979, 108, 356-388.

HyDe, T. S., \& Jenkins, J. J. Differential effects of incidental tasks on the organization of recall of a list of highly associated words. Journal of Experimental Psychology, 1969, 82, 472-481.

Lortus, G. R., \& Lortus, E. F. Human memory: The processing of information. Hillsdale, N.J: Erlbaum, 1976.

Posner, J. I., \& Snyder, C. R. R. Attention and cognitive control. In R. L. Solso (Ed.), Information processing and cognition: The Loyola symposium. Hillsdale, N.J: Erlbaum, 1975.

Smith, S. M. Remembering in and out of context. Journal of Experimental Psychology: Human Learning and Memory, 1979, $5,460-471$.

Smith, S. M., Glenberg, A., \& Bjork, R. A. Environmental context and human memory. Memory \& Cognition, 1978, 6, 342-353.

Strand, B. Z. Change of context and retroactive inhibition. Journal of Verbal Learning and Verbal Behavior, 1970, 9, 202-206.

Thomson, D. M., \& Tulving, E. Associative encoding and retrieval: Weak and strong cues. Journal of Experimental Psychology, 1970, 86, 255-262.

ZENTALL, T. R. Effects of context change on forgetting in rats. Journal of Experimental Psychology, 1970, 86, 440-448.

(Received for publication August 27, 1981.) 